\title{
Posterior scalloping of vertebral bodies in uncontrolled hydrocephalus
}

\author{
C. NORMAN SHEALY, ${ }^{1}$ MARJORIE LEMAY, ${ }^{2}$ AND FUAD S. HADDAD ${ }^{3}$ \\ From the Departments of Neurosurgery and Radiology, University Hospitals, Cleveland, Ohio, U.S.A., and \\ the American University of Beirut, Lebanon
}

The spinal canal normally increases in size until about the tenth year when the epiphyses fuse between the arches of the spine and the vertebral bodies. Enlargement of the canal after this time is manifested by flattening and thinning of the pedicles, increase in the interpediculate and saggital diameters of the canal, and posterior scalloping of the vertebral bodies. The majority of intraspinal tumours do not cause enlargement of the spinal canal because some tumours invade the vertebral bodies rather than enlarge the canal, and most intraspinal tumours produce marked neurological symptoms so that surgery is performed before changes occur in the pedicles of the vertebral bodies.

Posterior scalloping of vertebral bodies with localized enlargement of the spinal canal usually denotes the longstanding presence of a mass lesion but scalloping occasionally occurs in patients without a mass lesion being present within the canal. Most of those patients having a vertebral scalloping but no mass lesion have generalized neurofibromatosis and the bone changes have been attributed generally to a non-specific mesenchymal defect or developmental failure of the vertebrae.

The discovery of two patients with generalized posterior scalloping throughout most of the spinal canal associated with communicating hydrocephalus has prompted a review of the pathogenesis of posterior scalloping of the vertebral bodies. Two less striking cases have also been found.

CASE REPORTS

CASE 1 (A.U.H. 157-424) A 15-18-year-old Palestinian refugee, who had been born in Ghazeh and lived in an UNRWA camp, entered the American University Hospital in Beirut, Lebanon, with severe headaches and a disturbed gait.

Six years before admission, while walking, he suddenly developed cervical pain and a severe, throbbing frontal

${ }^{1}$ Department of Neurosurgery, University Hospitals, Cleveland, Ohio 44106.

${ }^{2}$ Department of Radiology, Peter Bent Brigham Hospital, Boston, Massachusetts.

${ }^{3}$ American University of Beirut. headache; he also had pain in the lumbar region and down his legs. Stiffness of the neck was present for two to three weeks. He continued to have intermittent headaches which were occasionally accompanied by vomiting. Mental development had been apparently normal before the illness but he had become dull during the period after the accident and he began to walk with some difficulty. For three or four months before admission there had been polydypsia and polyuria. It was stated that he urinated 20 to 30 times a day and three or four times at night, passing about $200 \mathrm{ml}$. each time.

The patient was a thin, poorly oriented boy who walked with a stiff, ataxic gait. He had bilateral papilloedema. Except for hyperactive Babinski's and spastic lower extremities, the neurological examination was not otherwise remarkable.

His temperature was normal and examination of the blood showed a normal number of red and white cells.

At lumbar puncture with the patient on his side, the cerebrospinal fluid pressure was recorded as $10 \mathrm{~mm}$. of mercury and rose to 46 with jugular compression. The spinal protein was $1,600 \mathrm{mg} . \%$; chloride, $113 \mathrm{mEq} . / \mathrm{l}$.

Films of the skull showed separated sutures and an enlarged sella. On antero-posterior spine films, the interpediculate spaces were widened throughout and lateral views showed widening of the saggital diameter of the cervical canal and the enlargement of the rest of the spinal canal was manifested by scalloping of the vertebral bodies which began in the mid-thoracic region and became deeper in the lumbar and sacral region (Figs. 1 and 2).

A small amount of air introduced into the lumbar subarachnoid space went easily up into the lateral ventricles and showed them to be very large (Fig. 3).

A myelographic study using $90 \mathrm{ml}$. Pantopaque demonstrated a very wide spinal canal without evidence of any tumour. The Pantopaque filled diverticula at the nerve roots in the lumbar region (Fig. 4).

A ventriculo-atrial shunt was recommended for the communicating hydrocephalus but the patient refused surgery and left the hospital.

CASE 2 W.L. (C. M.G.H. No. 189752) This 23-year-old Negro man entered Cleveland Metropolitan General Hospital in 1964, because of a weak right leg.

The patient had 'always' had a large head and had been well-coordinated until four years previously when he fell 


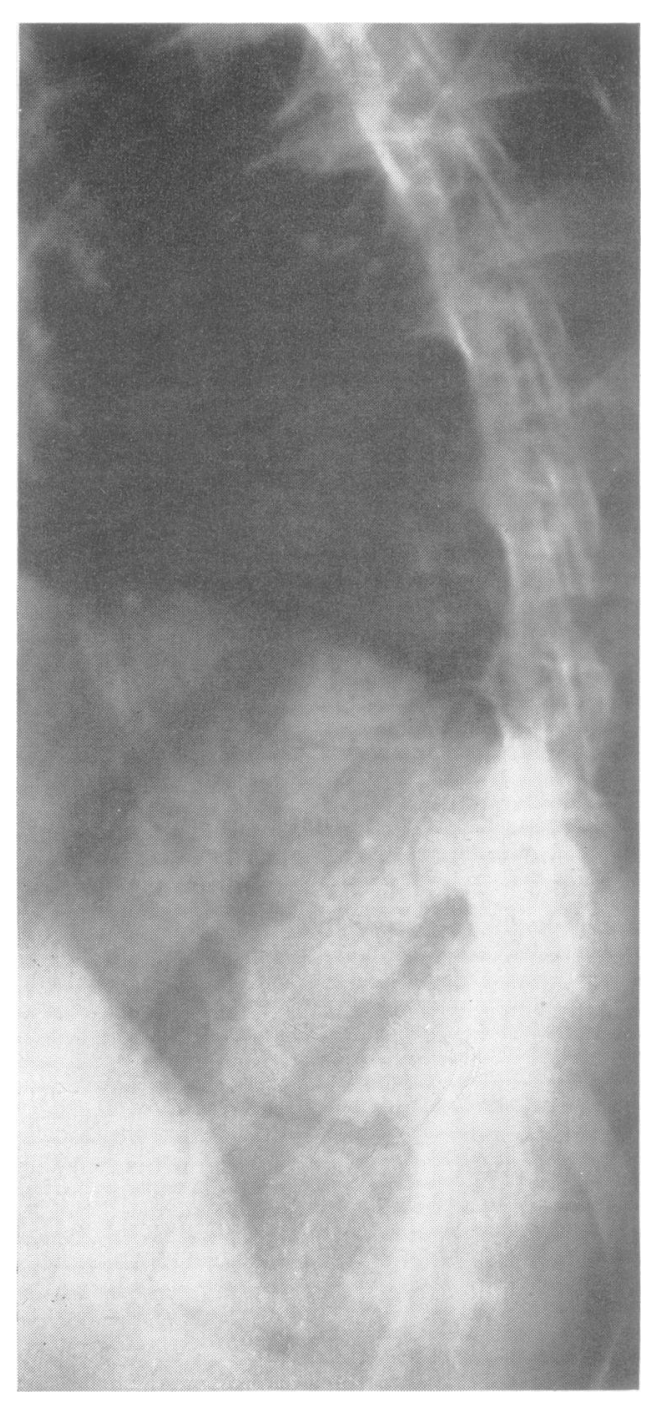

FIG. 1

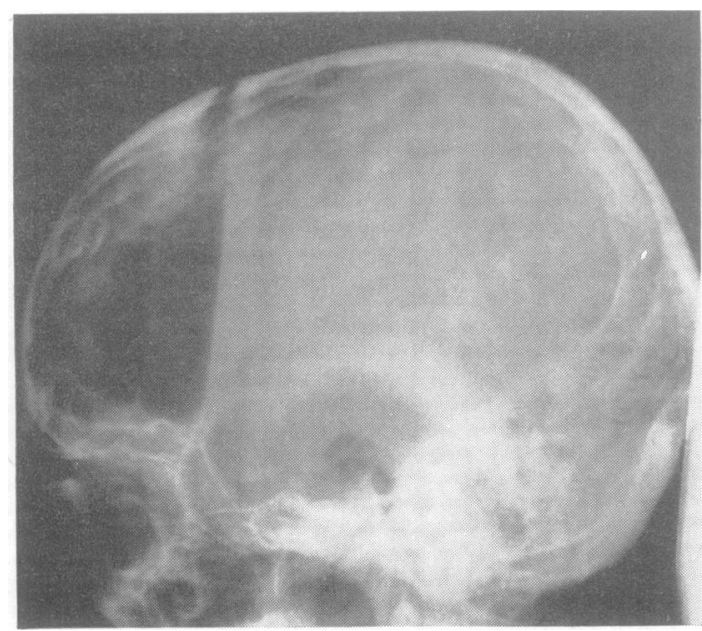

FIG. 3

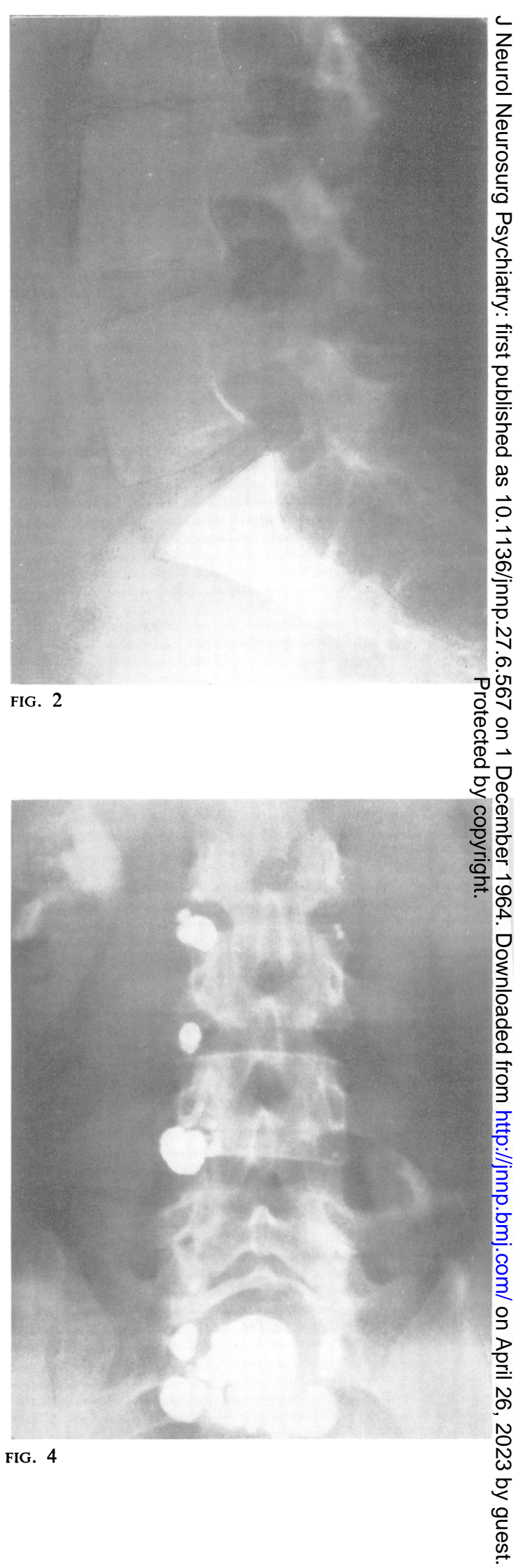



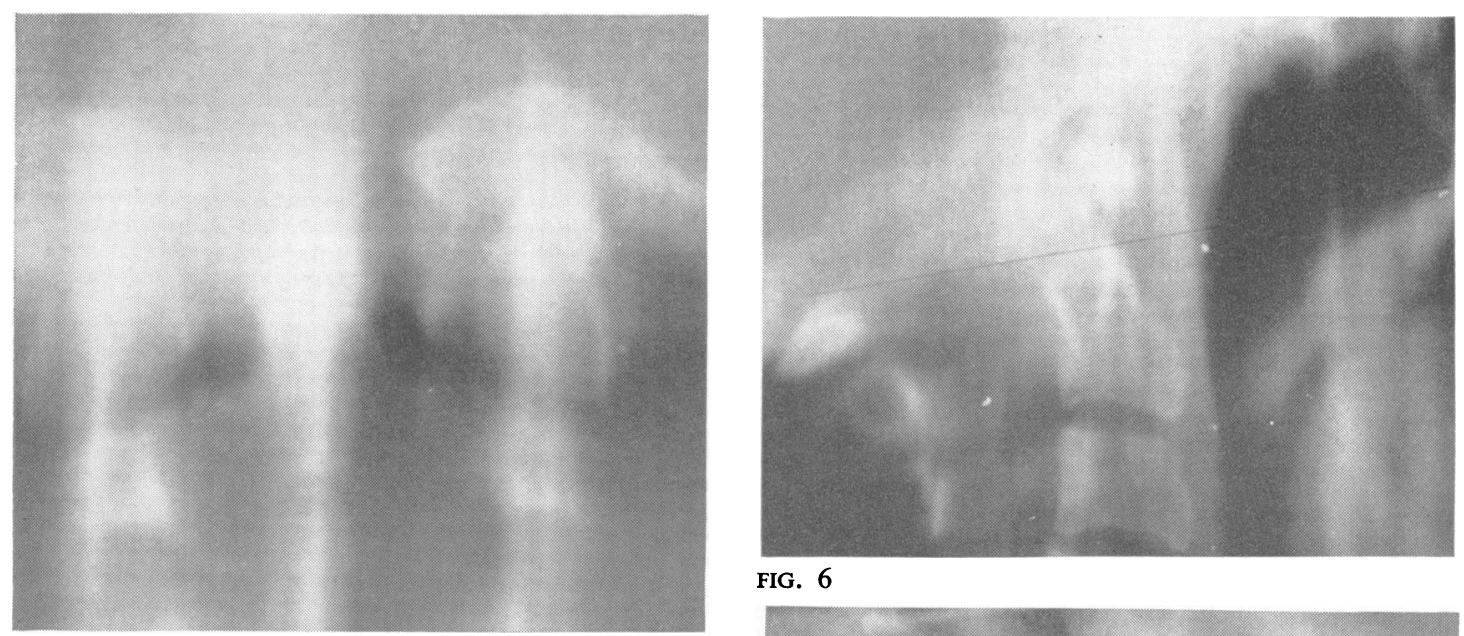

FIG. 6

FIG. 5

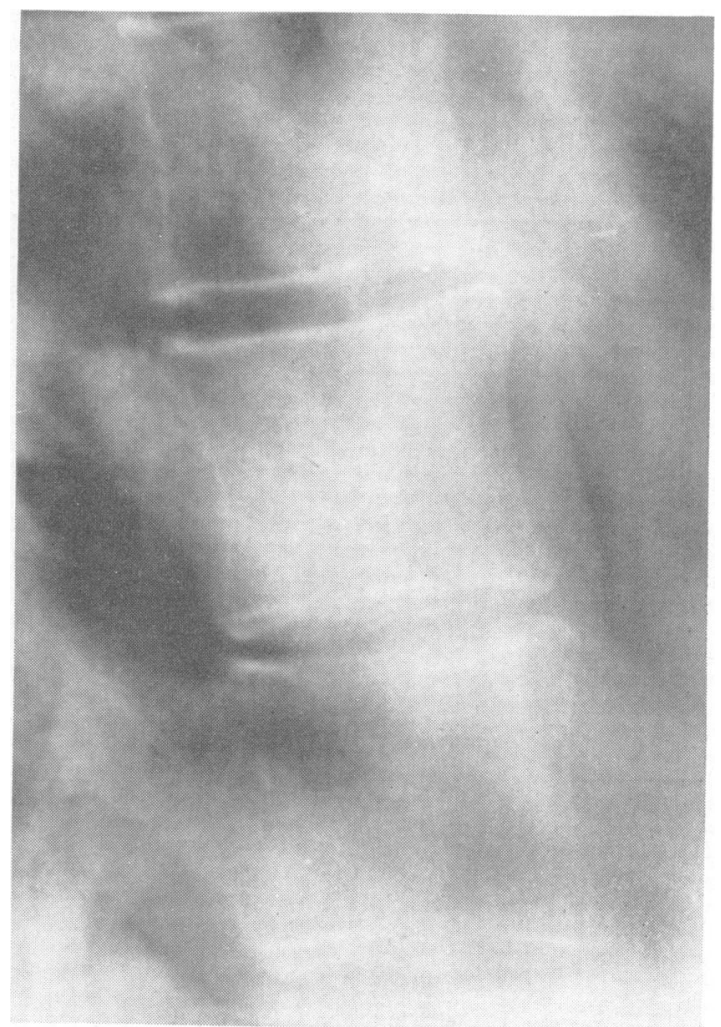

FIG. 8 ,

FIG. 1. Posterior vertebral scalloping, thoracic spine, case 1 .

FIG. 2. Lumbar spine, case 2.

FIG. 3. Pneumoencephalogram, case 1.

FIG. 4. Myelogram, case 1, showing multiple diverticuli.

FIG. 5. Antero-posterior laminagrams of odontoid region, case 2, demonstrating basilar impression.

FIG. 6. Lateral laminagram of odontoid region, case 2.

FIG. 7. Lumbar scalloping, case 2.

FIG. 8. Mild thoracic scalloping, case 2. 
and developed a limp. This had progressed over the four years and he had recently developed generalized headaches.

General physical examination was not remarkable.

On neurological examination, the head circumference was $68 \mathrm{~cm}$., and his I.Q. on the full-scale Wechsler test was 67 . The patient was alert and well-oriented. Visual acuity was O.U. 20/30; no papilloedema. There was mild to moderate weakness of the entire right foot, minimal weakness of the entire left leg, and moderate bilateral spasticity of the legs. There was mild ataxia of both legs.

An E.E.G. showed focal and diffuse slow activity with some focal spikes.

Lumbar puncture gave an opening pressure of $200 \mathrm{~mm}$.; the cerebrospinal fluid was clear and colourless with protein of $35 \mathrm{mg}$. per $100 \mathrm{ml}$. and sugar of $68 \mathrm{mg}$. per $100 \mathrm{ml}$.

Skull and cervical spine films revealed platybasia with basilar impression (Figs. 5 and 6). In addition there was considerable posterior vertebral scalloping in the lumbar region (Fig. 7) and somewhat less in the thoracic area (Fig. 8).

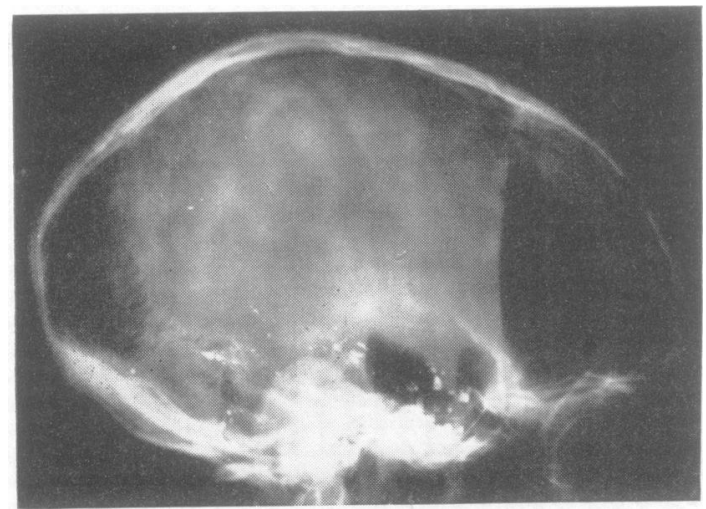

FIG. 9. Ventriculogram, case 2.

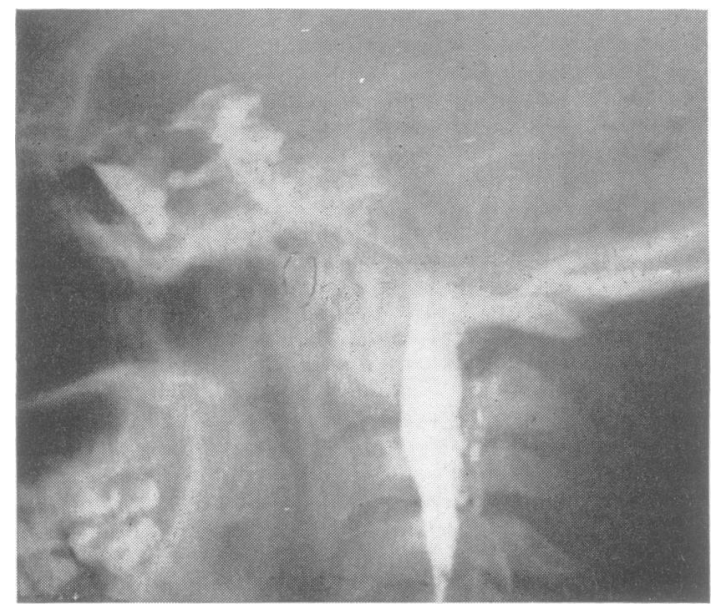

FIG. 10. Cervical myelogram, case 2.
A pneumoencephalogram was unsuccessful. A ventro culogram revealed marked hydrocephalus (Fig. 9) wit no communication with the lumbar cerebrospinal fluid $\subseteq$

A myelogram showed no unexpected abnormalities of the cervical region (Fig. 10) but, unfortunately, lumbaf myelogram films were not obtained.

The patient developed rapidly progressive symptoon matic increased intracranial pressure and was treate with a ventriculo-jugular shunt. Thereafter, he slowl but gradually improved and at discharge from hospita he was walking without aid, although the legs were stili spastic.

We have searched widely for further cases of asso듬 ciated hydrocephalus and posterior vertebral sca $\overline{5}$. loping. In a large number of early hydrocephalics we have not seen the scalloping. However, in two case of incompletely controlled hydrocephalus we have seen posterior scalloping of one lumbar vertebro One child was 5 years of age (J.B.; U.H. no. $801=$ 403) and the other 7 (L.W.; U.H. no. 774-124 $\vec{\omega}$ Both patients are younger than our other two cases: and have had congenital hydrocephalus which has been incompletely controlled during at least part of their early growth. In addition to the local mild scalloping there is lumbar interpedicular widening

\section{DISCUSSION} Intraspinal neoplasms are the most frequent cause्尺ेaf localized enlargement of the canal (Rasmussern Kernohan, and Adson, 1940; Broager, 1\$s Tucker, Aramsri, and Gardner, 1962). Neurofile mata and meningiomas, occurring with almost equal incidence, are the common intraspinal tumour 8

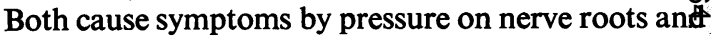
the cord and they are usually diagnosed before they are large enough to cause bone changes. Broage (1953) reported local changes in the spine in nin of 86 patients with meningiomas. Enlargement of the canal, shown by an increase of 1 or $2 \mathrm{~mm}$. of the interpediculate distance, never involved more that one vertebral body. Even localized scalloping adjacent to an enlarged intervertebral foramen is rarely caused by a dumb-bell type meningioma. Borfe changes are more frequently seen with spinat. neuromas, and Broager reported local radiologica changes in 22 of 43 cases. An increased interpedicu? lar distance of 1 or $2 \mathrm{~mm}$. was seen in 18 patient Posterior excavation of a single vertebral body was noted in five patients. In only two was there scallop ing in more than one vertebral body; one, a woman 50 years of age with back symptoms of at least $1 \frac{9}{4}$ years, showed excavation of L3, 4, and 5, and the second, a woman 44 years of age with back symp. toms for at least nine years, had posterior excavatiogs of the upper part of the sacrum. 
Diffuse dilatation of the spine extending over several vertebrae is more frequent with gliomas, including ependymomas, than neurofibromas. Dyke (1941) reported that diffuse dilatation of the spinal canal was rare with gliomas other than ependymomas of the filum terminale. Vertebral changes were noted in 15 of 45 patients with gliomas studied by Broager (1953). Nine of the 15 were in the lumbar region and three each in the cervical and thoracic regions. Dilatation of the spinal canal in the gliomas of this region extended over four or five vertebral bodies. The three thoracic gliomata caused changes in one, five, and six vertebrae respectively. Nine of 17 gliomas in the lumbar region in Broager's series caused changes involving several vertebral bodies. The thoracic gliomas were localized on plain films by an increase in the interpediculate diameter of the spine but the lumbar cases showed vertebral body excavations as well. Ependymomas are the common gliomas causing excavations of the lumbar vertebral bodies.

Rare neoplasms causing localized dilatation of the spinal canal and excavations of the vertebral bodies are vascular tumours, such as haemangioendotheliomas and haemangiomas and lipomas. Meredith, Lyerly, Bosher, Kay, and Old (1958) reported a postero-mediastinal haemagioma measuring $3 \times 5$ $\mathrm{cm}$., which caused rib erosion and extended into the spinal canal through an enlarged intervertebral foramen. The patient was a young girl who had difficulty in walking for a year. Of 15 cases of dumbbell tumours of the spine reported by Naffziger and Brown (1933), four were diagnosed as haemangioendotheliomas. Intraspinal lipomas may cause localized enlargement of the canal with posterior scalloping of several vertebrae, but, according to Ehni and Love (1945), they constitute only $1 \%$ of the primary intraspinal tumours in all age groups. They are more common in young people. They are commonly associated with congenital defects such as spina bifida, hairlip, pilonidal cyst, and hydrocephalus. Intrathoracic and mediastinal lipomas do occur but only one case has been reported of an intrathoracic lipoma with a dumb-bell extension into the spinal canal causing cord compression, and the spine films were normal in this case (Maier, 1962). Intraspinal lipomas will not, therefore, be confused with an intrathoracic meningocele.

Intraspinal cysts are rare but when present they may be large and frequently cause posterior excavations of several vertebral bodies. Murray (1959) reported shallow scalloping of the lumbar spine in a patient with a large intradural arachnoid cyst but most of the cysts have been located in the thoracic canal. Deeper excavations are usually caused in the sacrum by Tarlov's perineural cysts than by the cysts elsewhere in the spine. Cloward and Bucy
(1937) noted the association of Scheurman's disease, 'kyphosis dorsalis juvenilis', and thoracic arachnoid cysts, and suggested that the osteochondritis and kyphosis were caused by long-standing pressure of the cyst on the epidural veins and resulted in dystrophic bone changes. Good, Adson, and Abbott (1944) reviewed 20 cases of spinal extradural arachnoid cyst and added one case of their own. They stated that an enlarged spinal canal, kyphosis dorsalis juvenilis, and erosions of the vertebra are not found in any other condition. Not all of the cases reviewed by Cloward and Bucy (1937) showed appreciable scalloping; in fact, the cases with the most marked kyphosis seemed to show the least scalloping.

Localized enlargement of the spinal canal, manifested usually by an increase in the interpedicular diameter of the canal, may occur in the absence of a tumour associated with congenital anomalies of the spine and cord such as fusion defects and myelodysplasia (Jefferson, 1955; Walker, 1944; Neuhauser, Harris, and Berrett, 1958). Walker reported four such cases but one of his cases had a lipoma at the site of greatest dilatation of the canal, another a hydromelia with the cavity extending dorsal to the cord, and the third an angiomatous neoplasm. Jefferson (1955) reported two patients without mass lesions who underwent surgery because of thinned pedicles and localized increased interpediculate distances in the lower thoracic and upper lumbar region. One of these patients had short spinous processes at $\mathrm{T}-11$ and 12 and a fusion defect at T-11. Another congenital anomaly of the spine easily confused with the bone changes of a tumour mass is the absence of a single pedicle which gives the radiological appearance of a large intervertebral foramen. Steinbach, Boldrey, and Sooy (1952) described one and Hadley (1951) three such cases.

Intrathoracic meningoceles represent one of the well-recognized causes of posterior vertebral scalloping. Reviews of the published reports of intrathoracic meningoceles by Hillenius (1959) and del Buono and Osácar (1961) list 46 cases. It is possible that one or two of the patients are recorded more than once. The records are not all complete but 33 of the 46 patients were noted as having neurofibromatosis. The common radiographic features have been a posterior mediastinal mass, enlarged intervertebral foramina, localized enlargement of the spinal canal manifested by an increased interpediculate measurement and posterior vertebral body excavations and kyphoscoliosis, on the convex side. Occasionally the ribs are spread and their adjacent margins at the site of the meningocele are eroded.

Some patients with localized enlargement of the spina! canal and deep scalloping of several vertebral 
bodies have been studied who had neither meningoceles nor tumours (Heard, 1962; Braun, 1955; Holt and Wright, 1948) and the posterior vertebral excavations in these patients are the most difficult to explain. Most of these cases have had generalized neurofibromatosis (Heard, 1962; Hagelstam, 1946). A case reported by Jefferson (1955) and another case reported by Schröder (1956) did not have stigmata of neurofibromatosis and it has been suggested that these two cases may represent a forme fruste of neurofibromatosis. Other, more common, bone changes seen with neurofibromatosis are scoliosis, erosive lesions (occurring usually adjacent to tumours and possibly in rib margins), overgrowth of bone with thickening of the trabeculae, underdevelopment with shortening of the bones of one or more extremity, congenital bowing and pseudarthrosis and intraosseous cystic changes. Holt and Wright (1948), in a very comprehensive review of the bone changes in 127 patients with neurofibromatosis, concluded that the bone changes most likely represented a disturbance of nutrition incident to faulty innervation, inadequate blood supply, or atrophy of disuse.

The vertebral body changes in patients with neurofibromatosis and a thoracic meningocele can be explained by pressure from an intraspinal cyst which herniated through an intervertebral foramen. The excavations of the vertebral bodies are usually asymmetrically placed, and lie inder the cyst. The kyphosis and degenerative changes at the margins of the vertebra and the slight anterior wedging of the vertebral bodies even resemble somewhat the juvenile epiphysis seen in many of the young patients with thoracic arachnoid cysts. A patient with cutaneous neurofibromatosis and a paravertebral mass reported by del Buono and Osácar (1961) showed at operation a large thoracic arachnoid cyst which extended through an enlarged intervertebral foramen into the thorax. Its intrathoracic portion was described as the size of a walnut and was seen on a chest film. Most of the reported cases of intrathoracic meningocele have had pneumomyelography or no myelographic studies so it is impossible even to speculate on the frequency of intraspinal cysts at the site of the meningocele. Lombardi and Morello (1963), in a comprehensive review of cysts of the spinal canal and nerve roots, stated that it was theoretically admissible to regard spinal extradural cysts and spinal meningoceles as two aspects of the same dysrhaphic condition. Extension of a thoracic extradural cyst along a nerve root for a short distance into an intervertebral foramen was noted in a patient by Strang and Tovi (1961). They postulated that the cyst had its origin from one of the lateral nerve roots to which it was closely attached. Multiple arachnoid protrusions were found in a case of a thoracic cyst reported by Nugent, Odom, and WoodhalF (1959).

A few authors have suggested that thoracie meningoceles represent meningeal herniations occur ring because of pre-existing osseous lesions, (Seng= piel, Ruzicka, and Lodmell, 1948; Moyer, Crameres and Duncan, 1957). The published cases followees over a period of time with an increase in size of the meningocele (Ameuille, Wilmoth, and Kudelskis. 1940; Ciaglia, 1952; Byron, Alling, and Samson 1949) make such an hypothesis untenable. Mosf authors seem to feel that the bone lesions in the patients with neurofibromatosis and vertebra? scalloping with and without meningoceles, are prob? ably due to primary 'bone dystrophy' and duraß weakness which allows the bone to be affected by the pulsations of the spinal fluid. It seems plausible that changes in the osseous development of vertebrae in a localized segment of the spine may occur with neuro $\vec{w}$ fibromatosis, and allow a few vertebrae to be ex? cavated by pulsating spinal fluid much as lateras vertebral scalloping occurs adjacent to an aneurysm of the thoracic aorta. Since vertebral bodies formed of apparently normal bone characteristically ex cavate beneath intraspinal cysts, vascular lesiogs: and slow growing tumours it would seem very pळs sible also that the vertebrae are normally develoned in the patients with neurofibromatosis and that the defect is primarily that of dural abnormality. primary dural effect with an expanding sac causBg. vertebral erosion was postulated by Whiteha एकse (1958).

In our first two patients, vertebral excavations wêteo shallow in the upper thoracic spine and deepeof lower in the spine where the hydrostatic pressure wa greatest. The myelogram showed in case 1 numerou? herniations at each lumbar nerve root and appeare similar to the case of a patient with neurofibro. matosis reported by Sammons and Thomas (1959क as 'extensive lumbar meningocele'. It is very prob? able that an enlarged spinal canal will also be foun $\bar{\Phi}$ in some of the infants with communicating hydro cephalus, just as it is enlarged even in small menin goceles. The increased intraspinal pressure which. must have been present in our first two patients fo믈 many years was present near the time of closure of the epiphysis at the junction of the arch and the bodies and caused not only widening of the spinal canal but also excavations of the vertebral bodies.

\section{SUMMARY}

Two cases of extensive posterior scalloping of the vertebral bodies in patients with long-standing hydrocephalus are presented.

Two additional cases with scalloping of only ons 
lumbar vertebra when partially controlled hydrocephalus has been present a shorter time are also noted. A review of the causes of posterior scalloping reveals no previously reported association between these entities.

The authors wish to thank Dr. Robert White, Chief of Neurosurgery Service, Cleveland Metropolitan Hospital, for permission to report case 2 .

\section{REFERENCES}

Ameuille, P., Wilmoth, P. and Kudelski, C. (1940). Méningocèle rachidienne à développement intrapleural. Bull. Soc. méd. Hôp. Paris, 56, 608-615.

Braun, H. (1955). Die dorsale Wirbelexkavation, ein selbständiges Symptom bei der Neurofibromatose Recklinghausen. Fortschr. Röntgenstr., 83, 844-847.

Broager, B. (1953). Spinal neurinoma. Acta psychiat. scand., suppl. 85.

Byron, F. W., Alling, E. E., and Samson, P. C. (1949). Intrathoracic meningocele. Journal thorac. Surg., 18, 294-303.

Ciaglia, P. (1952). Intrathoracic meningocele: Excision, with $3 \frac{1}{2}$ years follow-up. Ibid., 23, 283-292.

Cloward, R. B., and Bucy, P. C. (1937). Spinal extradural cyst and kyphosis dorsalis juvenilis. Amer. J. Roentgenol., 38, 681-706.

del Buono, M. S., and Osácar, E. M. (1961). Intrathoracic meningocele associated with cutaneous neurofibromatosis. Acta neurochir. (Wien), 9, 561-580.

Dyke, C. G. (1941). The roentgen ray diagnosis of diseases of the spinal cord, meninges, and vertebrae. In Surgical Diseases of the Spinal Cord, Membranes, and Nerve Roots, by C. A. Elsberg, p. 42-122. Hoeber, New York.

Ehni, G., and Love, J. G. (1945). Intraspinal lipomas. Arch. Neurol. Psychiat. (Chic.), 53, 1-28.

Good, C. Allen, Adson, A. W., and Abbott, K. H. (1944). Spinal extradural cyst (Diverticulum of spinal arachnoid). Amer. J. Roentgenol., 52, 53-56.

Hadley, L. A. (1951). Congenital absence of pedicle from the cervical vertebra: Report of three cases. Ibid., 55, 193-197.

Hagelstam, L. (1946). On the deformities of the spine in multiple neurofibromatosis. Acta chir. scand., 93, 169-193.

Heard, G., and Payne, Eric E. (1962). Scalloping of the vertebral bodies in von Recklinghausen's disease of the nervous system. (Neurofibromatosis). J. Neurol. Neurosurg. Psychiat., 25, 345351.
Hillenius, L. (1959). Intrathoracic meningocele. Acta med. scand., $163,15-20$.

Holt, J. F., and Wright, E. M. (1948). The radiologic features of neurofibromatosis. Radiology, 51, 647-663.

Jefferson, A. (1955). Localized enlargement of the spinal canal in the absence of tumour: a congenital abnormality. J. Neurol. Neurosurg. Psychiat. 18, 305-309.

Lombardi, G., and Morello, G. (1963). Congenital cysts of the spinal membranes and roots. British J. of Radiol., 36, 197-205.

Maier, H.C. (1962). Extradural and intrathoracic lipoma causing spinal cord compression. J. Amer. med. Ass., 181, 610-612.

Meredith, J. M., Lyerly, J. Jr., Bosher, L. Jr., Kay, S., and Old, L. (1958). Hemangioma of posterior mediastinum with cord compression in midthoracic region. Ibid., 166, 484-488.

Moyer, R. R., Cramer, H. R., and Duncan, G. G. (1957). Intrathoracic meningocele: A case report. Amer. J. Med., 22, 334-336.

Murray, R. O. (1959). Intradural arachnoid cyst of the lumbar spinal canal. British J. Radiol., 32, 689-692.

Naffziger, H. C., and Brown, H. A. (1933). Hour-glass tumours of the spine. Arch. Neurol. Psychiat. (Chic.), 29, 561-584.

Neuhauser, E. B. D., Harris, G. B. C., and Berrett, A. (1958). Roentgenographic features of neurenteric cysts. Amer. J. Roentgenol., $79,235-240$.

Nugent, G. R., Odom, G. L., and Woodhall, B. (1959). Spinal extradural cysts. Neurology (Minneap.), 9, 397-406.

Rasmussen, T. B., Kernohan, J. W., and Adson, A. W. (1940). Pathologic classification with surgical consideration, of intraspinal tumours. Ann. Surg., 111, 513-530.

Sammons, B. P., and Thomas, D. F. (1959). Extensive lumbar meningocele associated with neurofibromatosis. Amer. J. Roentgenol., 81, 1021-1025.

Schröder, G. (1956). Die dorsale Wirbelexkavation ein Symptom der Neurofibromatose Recklinghausen. Bruns' Beitr. klin. Chir., 193, 350-355.

Sengpiel, G. W., Ruzicka, F. F., and Lodmell, E. A. (1948). Lateral intrathoracic meningocele. Ibid., 50, 515-519.

Steinbach, H. L., Boldrey, E. B., and Sooy, F. A. (1952). Congenital absence of the pedicle and superior facet from a cervical vertebra. Radiology, 59, 838-840.

Strang, R. R., and Tovi, D. (1961). Congenital thoracic extradural cysts. Acta neurochir. (Wien), 9, 433-439.

Tucker, A. S., Aramsri, B., and Gardner, W. J. (1962). Primary spinal tumours: A seven-year study. Amer. J. Roentgenol., 87, 371-374.

Walker, A. E. (1944). Dilatation of the vertebral canal associated with congenital anomalies of the spinal cord. Ibid., 52, 571-582.

Whitehouse, D. (1958). Quoted by Heard, G. and Payne, Eric E. (1962). Scalloping of the vertebral bodies in von Recklinghausen's disease of the nervous system. J. Neuro. Neurosurg. Psychiat., 25, 345-351. 